\title{
FREE VOLUME IN EPOXY-COAL RESINS STUDIED BY POSITRON ANNIHILATION
}

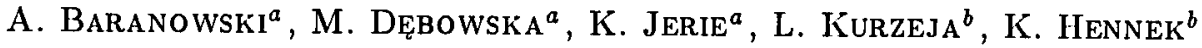 \\ AND J. RUDZIŃsKA-GIRULSKA ${ }^{a}$ \\ ${ }^{a}$ Institute of Experimental Physics, University of Wrocław \\ Maxa Borna 9, 50-204 Wrocław, Poland \\ ${ }^{b}$ Institute of Coal Chemistry PAN, Sowińskiego 62, 44-100 Gliwice, Poland
}

In this paper the macroscopic properties of the tetrafunctional epoxy resin ( $N, N^{\prime}$-tetraglycidyl ether of diaminodiphenylmethane) cured by $4,4^{\prime}$-diaminodiphenylmethane, were studied. For the system the influence of various curing conditions on the glass temperature was investigated. Results obtained for two compositions: an unmodified one and a modified with coal were compared with information on the free volume given by the positron annihilation technique.

PACS numbers: $71.60 .+z, 78.70 . B j, 81.20 . S h, 82.30 .11 k$

\section{Introduction}

Epoxy resins are one of the most important thermosetting polymers and have wide use as structural adhesives, the organic matrix component for high performance fiber composites materials, and as encapsulating materials for electronic devices to protect them from moisture, dusts, shocks, and to secure electrical insulation. Recent development of technique and modern technology is followed by demand for materials of new qualities, especially ones from the group of composites and electrically resistant materials of higher thermal stability.

The properties of cured resins are connected with the chemical structure of resin, and curing agents, but also are strongly connected with curing condition. The chemical changes that accompany the cross-linking of an epoxy resin determine the chemical, mechanical, thermal and physical properties of cross-linked products (cross-linked epoxy resins). During the curing resins are transformed from liquid of low viscosity to solid state of a highly cross-linking network by chemical reactions of the reactive group.

On the other hand, coal is a porous material that contains mostly carbon and hydrogen [1]. Carbon is the most abundant component of it. The structure of coal is very complex and beside carbon and hydrogen it comprises a variety of functional groups, such as hydroxyl (-OII), methoxyl $\left(-\mathrm{OCH}_{3}\right)$, carbonyl $(-\mathrm{C}-\mathrm{O})$, carboxyl (-COOH) and amine $\left(-\mathrm{NH}_{2},-\mathrm{NII}\right)$. Due to these characteristics, coal as a natural product appears to be an extremely promising material in a set of organic cheap fillers or as a chemical component of polyblend, and composite materials. 


\subsection{Scheme of the possible reaction for epoxy group with primary amines}

In cross-linking process, growth and branching of the polymer chains is considered to occur in the liquid state where the system is soluble and fusible. The polymer chain then loses its solubility and fusibility, and the final reaction takes place in the solid state. Techniques for monitoring the curing process include the chemical ah spectroscopic analysis which are described elsewhere [2]. The processes mentioned above are given by formulae (1), (2), (3), (4) and in Fig. 1.

Scheme of the possible reactions for epoxy group with primary amines.

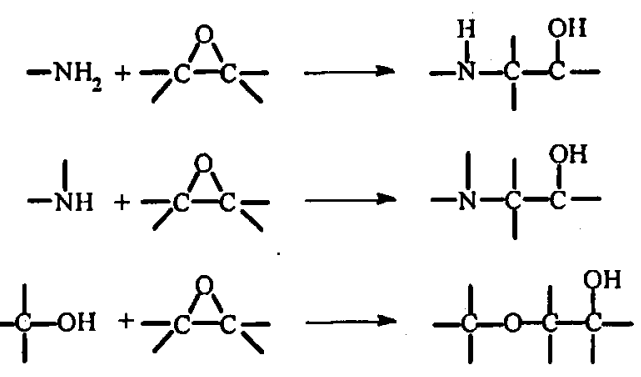

For tetraglycicyl ethers and primary diamines the first stage of cross-linking is<smiles>CCC1CO1</smiles>

A lot of methods to test the properties of the cured resins are known. The standard ones (as mechanical, electrical, chemical and thermomechanical) tests give macroscopic characteristics. To determine the microscopic properties positron annihilation spectroscopy (PAS) has been applied $[3,6,7]$. This enabled the examination of intermolecular space holes. PAS is thought to be promising and novel technique to evaluate the free volume of polymers, which influences the physical characteristics of them.

In this work we monitored physical behaviour of the pure epoxy resin and the one modified with coal by measuring the changes in termomechanical properties (the glass transition temperature $T_{\mathrm{g}}$ and the storage modulus $E^{\prime}$, by the dynamic mechanical thermal analysis, DMTA) and positron annihilation lifetime (PAL) spectra. 
a
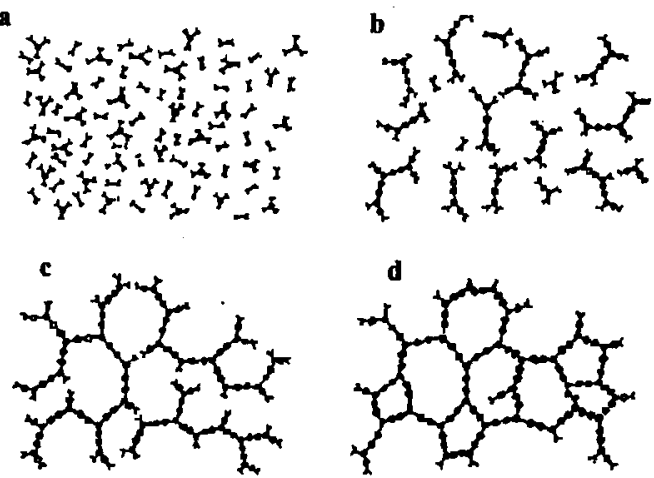

Fig. 1. Curing of thermoset. Cure begins with $A$-stage monomer(s) (a); proceeds via linear growth and branching to $B$-stage material below gel point (b); continues with formation of gelled but incompletely cross-linked network (c); finishes as fully cured $C$-stage thermoset (d).

On the basis of the positron lifetime measurements we estimated the mean size of the free volume in samples studied after different time of curing and that had been cured at different temperatures.

\section{Experimental}

\subsection{Materials}

Epoxy resin $-N, N^{\prime}$-tetraglycidyl ether of diaminodiphenylmet(TGDMA).

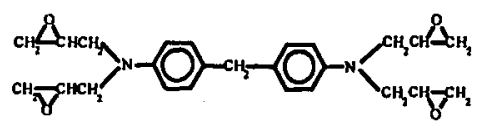

Trade mark Epikote 604 received from Shell Company (Netherland).

Curing agent $-4,4^{\prime}$-diaminodiphenylmethane (MDA).

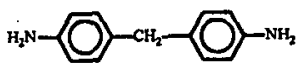

The resin and curing agent were used without further purification.

Coal was finely ground $(<0.2 \mathrm{~mm})$, and dried in vacuum at $90^{\circ} \mathrm{C}$ for 24 hours. We used coal to epoxy ratio 30:70 (Table I). 


\subsection{Preparation of the samples}

Four samples were studied (two without coal and two including coal, Nos. 1, 2 and 3, 4 in Tables I and II). The samples were prepared by mixing the resin and the hardener in the stoichiometric quantity, degassed in vacuum at $100^{\circ} \mathrm{C}$ and than poured into the stainless form of dimensions $50 \times 10 \times 2 \mathrm{~mm}^{3}$ and left in the oven at $100^{\circ} \mathrm{C}$ for 15 hours. Two of them (one including coal-sample No. 4 and one without coal-sample No. 2) were post-cured for 4 hours at $150^{\circ} \mathrm{C}$ and for 4 hours at $200^{\circ} \mathrm{C}$. Further details of the preparation of samples are given in $[4,5]$.

\section{TABLE I}

Coal content.

\begin{tabular}{c|c|c|c|c|c}
\hline \hline Coal 715 & \multicolumn{5}{|c}{ Characteristics of coal daf. [\%] } \\
\cline { 2 - 6 }$($ German) & $\mathrm{C}$ & $\mathrm{H}$ & $\mathrm{S}$ & $\mathrm{O}+\mathrm{N}$ & $\mathrm{Ash}$ \\
\cline { 2 - 6 } & 63.34 & 4.79 & 0.59 & 31.51 & 10.65
\end{tabular}

\section{TABLE II}

Results of DMTA measurements.

\begin{tabular}{c|c|c|c}
\hline \hline Sample & $\tan \delta$ & $\begin{array}{c}E^{\prime}[\mathrm{MPa}] \\
(\text { at 30 })\end{array}$ & $T_{\mathrm{g}}\left[{ }^{\circ} \mathrm{C}\right]$ \\
\hline 1 & 0.0524 & 1784.8 & 140.9 \\
& 0.1799 & & 247.5 \\
2 & 0.2180 & 1642.6 & 244.3 \\
3 & 0.0649 & 923.1 & 135.9 \\
& 0.1498 & & 258.3 \\
4 & 0.1897 & 1891.1 & 244.9
\end{tabular}

\subsection{DMTA studies}

The dynamic mechanical thermal analysis is a new technique that enables both mechanical and flow properties (basic physical properties) of materials to be observed and determined with respect to changes in stress, strain, frequency, temperature and time. The kind of movement and mobility of different materials depends on their internal structure (morphology) and external parameters (strain, temperature). It reveals in measurements of such quantities as the storage modulus $\left(E^{\prime}\right)$ and the loss factor $(\tan \delta)$ of the composition. The values of the modulus of a system are connected with the cross-link density of the system. The glass temperature $\left(T_{\mathrm{g}}\right)$ of materials is determined from the $\tan \delta$ vs. temperature plots as the value of the temperature corresponding to the position of the maximum. Only one value of $T_{\mathrm{g}}$ suggests that the cross-linked composite is homogeneous and fully cured (state $d$ in Fig. 1). Two or more values of $T_{\mathrm{g}}$ suggest that the cross-linked resin consists of highly cross-linked modules (highest $T_{\mathrm{g}}$ ) immersed in an intermodulator matrix of lower cross-link density (lower $T_{\mathrm{g}}$, state $c$ in Fig. 1). The conditions of curing (time and temperature) can change the value of $T_{\mathrm{g}}$ (the 

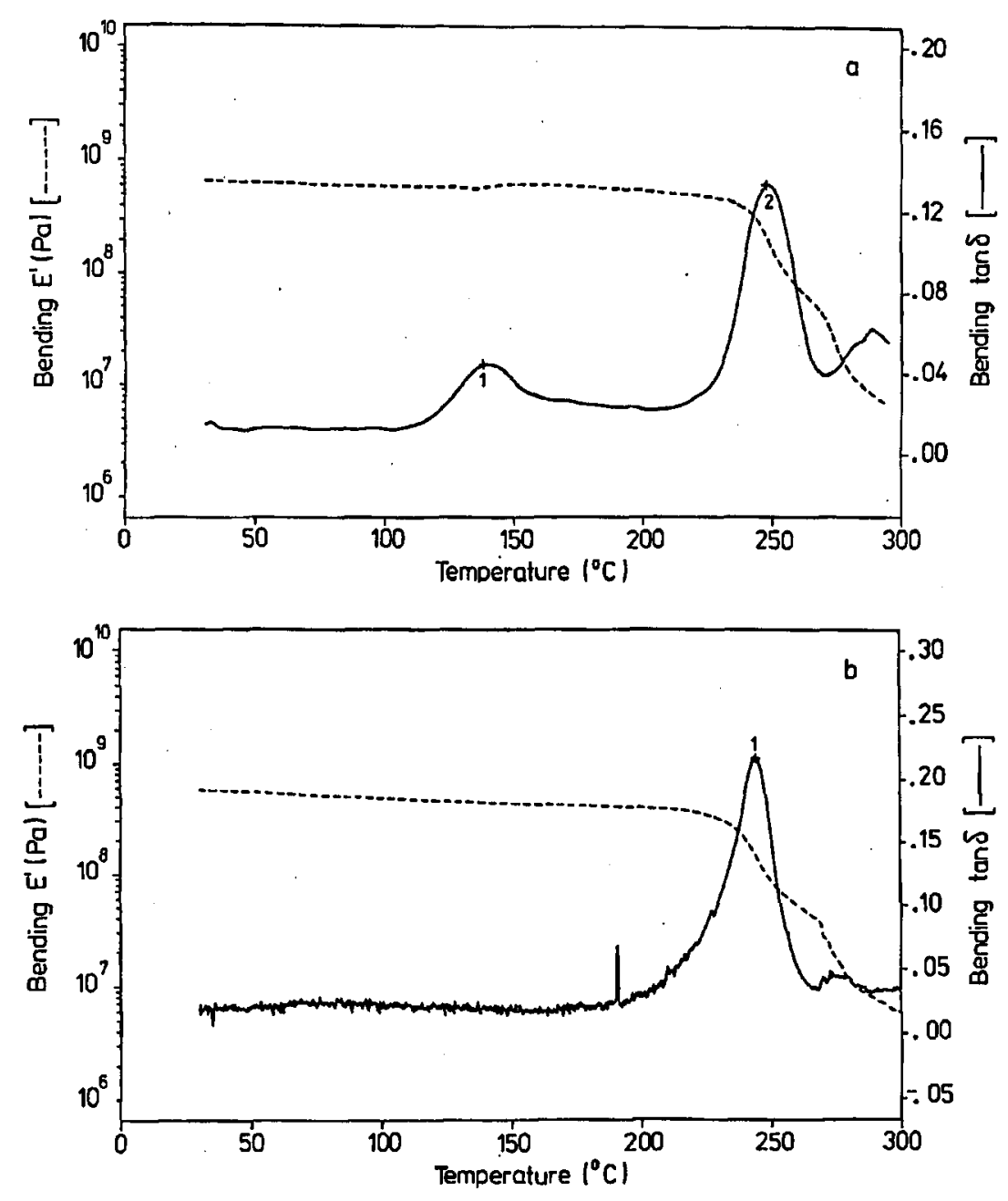

Fig. 2. $\tan \delta$ and $E^{\prime}$ vs. temperature for the pure epoxy resin TGDMA-MDA: (a) $15 \mathrm{~h}$ at $100^{\circ} \mathrm{C}$, (b) $15 \mathrm{~h}$ at $100^{\circ} \mathrm{C}$ (post-curing $4 \mathrm{~h}$ at $150^{\circ} \mathrm{C}$ and $4 \mathrm{~h}$ at $200^{\circ} \mathrm{C}$ ).

state $c$ transforms into the state $d$ in Fig. 1). In case of composite materials (two or more polymers) one value of $T_{\mathrm{g}}$ shows that components are miscible, but more values of $T_{\mathrm{g}}$ show that components are not miscible. Another possible explanation is that the material consists of different phases or not fully cured.

The samples were examined by DMTA (Polymer Labs) using the frequency of $1 \mathrm{~Hz}$ and the heating rate equal to $3^{\circ} \mathrm{C} / \mathrm{min}$ in the temperature range of $30-300^{\circ} \mathrm{C}$. The spectra of the DMTA analysis for the pure resin TGDMA-MDA are given in Fig. 2. The spectra of DMTA measured for the resin modified with coal are of the same character, i.e. two peaks occur in the plot of $\tan \delta$ vs. temperature in case of the resin modified with coal but not post-cured while only one peak remains in 
the plot after the post-curing. It is worthy to mention that the single peak in the plot $\tan \delta$ vs. temperature for sample 4 is much broader than the one for sample 2. In Table II values of $\tan \delta$ and $T_{\mathrm{g}}$ corresponding to the peaks in the plots as well as the values of $E^{\prime}$ at $30^{\circ} \mathrm{C}$ are given for all the samples.

\subsection{PAL studies}

PAL measurements were performed at room temperature. A fast coincidence system with $\mathrm{BaF}_{2}$ scintillators and photomultipliers of XP2020Q type was used. Further details of the spectrometer will be given elsewhere [8]. The positron source ${ }^{22} \mathrm{Na}$ of activity $20 \mu \mathrm{Ci}$ was deposited between two identical thin Hostaphan foils $\left(0.8 \mathrm{mg} \cdot \mathrm{cm}^{-2}\right.$ each) and then sandwiched between the samples under investigation. A typical decay curve contained about $1.5 \times 10^{7}$ counts and had the peak to background ratio of $2 \times 10^{5}$. The PAL spectra were fitted with a sum of three exponentials convoluted with the resolution function of the lifetime spectrometer (a sum of two Gaussians) plus a constant background using the program POSITRONFIT [9].

\section{Results and discussion}

The product $\tau_{3} I_{3}$ of the longest lifetime $\left(\tau_{3}\right)$ and the intensity of the longest-lived component $\left(I_{3}\right)$ given in Table III can be considered as a rough measure of the free volume in the polymer as it was shown in [10]. The relative changes in the value of the product for studied samples denoted as $\Delta Y$ and related to sample No. 1 are also given as well as the value of the mean radius of the free volume $R$ estimated on the basis of the $\tau_{3}$ values according to the formula given by Tao [11] and Eldrup et al. [12].

\section{TABLE III}

Results of PAL measurements.

\begin{tabular}{c|c|c|c}
\hline \hline Sample & $I_{3} \tau_{3}[\mathrm{~ns}]$ & $\Delta Y[\%]$ & $R[\mathrm{~nm}]$ \\
\hline 1 & $28.6(0.5)$ & 0.0 & $0.251(0.001)$ \\
2 & $25.3(0.5)$ & 11.4 & $0.263(0.001)$ \\
3 & $26.1(0.5)$ & 8.6 & $0.257(0.001)$ \\
4 & $22.3(0.5)$ & 22.0 & $0.264(0.001)$
\end{tabular}

The final conclusions are as follows:

1. Average size of free volumes does not totally depend on the post-curing and adding of coal.

2. The system TGDMA + MDA as it is already known from literature needs post-curing at the temperature $200^{\circ} \mathrm{C}$ (only one peak in the plot of $\tan \delta$ vs. temperature, Fig. 2b). The adding of coal to the svstem does not cancel the necessity of the post-curing nor does it affect the value of $T_{\mathrm{g}}$ (cf. data for samples 1, 2 and 3, 4 in Table II). Both the adding of coal and the post-curing cause a noticeable reduction of the contribution of the free volume in the total volume of the sample. 
3. The post-curing causes the decrease in the value of the storage modulus, $E^{\prime}$ as a consequence of the increase in the cross-link density. It means that the post-curing resulted in the fully cured resin (the only value of $T_{\mathrm{g}}$ ) and it is followed by the decrease in the amount of the free volume.

4. The samples including coal, after post-curing show the larges decrease in the free volume.

5. The single glass temperature for the epoxy resin modified with coal and post-cured shows that introduction of coal combined with the post-curing generates homogeneous properties on the macromolecular scale, but the broadening of the $\tan \delta$ peak, observed for sample 4 , is probably due to the tracks of coal in the epoxy network as a result of reaction of functional groups present in coal with epoxy groups. A consequence of this may be the additional reduction of free volume in the total volume of the sample in comparison with sample 2 .

This work was partially supported by grant No. 0109/52/93/04 and GBW/94/5/IFD.

\section{References}

[1] J.G. Spight, The Chemistry and Technology of Coal, M. Dekker, New York 1983.

[2] Y. Tanaka, R.S. Bauer, in: Epoxy Resins. Chemistry and Technology, Ed. C.A. May, M. Dekker, New York 1988, p. 300.

[3] T. Suzuki, Y. Oki, M. Numajiri, T. Miura, K. Kondo, Y. Shiomi, Y. Ito, J. Appl. Polym. Sci. 49, 1921 (1993).

[4] L. Kurzeja, K. Hennek, to be published in Proceedings of 8th Int. Conf. on Surface and Colloid Science, Adelaide (Australia) 1994.

[5] L. Kurzeja, K. Hennek, J. Appl. Polym. Sci., in press.

[6] G.H. Dai , Q. Deng, J. Liu, H. Shi, C.M. Huang, Y.C. Jean, J. Phys. IV (France) 3, 233 (1993).

[7] Y.C. Jean, Maler. Sci. Forum 105-110, 309 (1992).

[8] J. Chojcan, to be published.

[9] P. Kirkegaard, N.J. Pedersen, M. Eldrup, PATFIT-88: A Data Processing System for Positron Annihilation Spectra on Mainframe and Personal Computers, Tech. Rep. Ris $\emptyset-M-2740$, Ris $\varnothing$ National Laboratory, Roskilde 1989.

[10] V.V. Volkov, A.V. Goldanskii, S.G. Durgaryan, V.A. Onishchuk, V.P. Shantarovich, Yu.P. Yampol'skii, Vysokomol. Soed. A 29, 192 (1987).

[11] S.J. Tao, J. Chem. Phys. 56, 5499 (1971).

[12] M. Eldrup, D. Lightbody, J.N. Sherwood, Chem. Phys. 63, 51 (1981). 